\title{
Comparison of the growth performance and long-chain PUFA biosynthetic ability of the genetically improved farmed tilapia (Oreochromis niloticus) reared in different salinities
}

\author{
Cuihong You ${ }^{1} \dagger$, Fangbin $\mathrm{Lu}^{1} \dagger$, Shuqi Wang ${ }^{1}$, Cuiying Chen ${ }^{1}$ and Yuanyou $\mathrm{Li}^{2} *$ \\ ${ }^{1}$ Guangdong Provincial Key Laboratory of Marine Biotechnology, Shantou University, Shantou 515063 , \\ People's Republic of China \\ ${ }^{2}$ School of Marine Sciences, South China Agricultural University, Guangzhou 510642, People's Republic of China \\ (Submitted 4 June 2018 - Final revision received 7 November 2018 - Accepted 7 November 2018)
}

\section{Abstract}

To compare the growth and biosynthetic ability of long-chain PUFA (LC-PUFA) of the genetically improved farmed tilapia (GIFT) (Oreochromis niloticus) in different water salinities, an 8-week feeding trial was conducted on the GIFT juveniles at 0,12 and $24 \%$ (parts per thousand; ppt), respectively, with three isonitrogenous (32\%) and isolipidic (8\%) diets (D1-D3). Diet D1 with fish oils (rich in LC-PUFA) as lipid source was used as the control, while D2 and D3 with vegetable oil (free LC-PUFA) blends as lipid source contained different ratios of linoleic acid (LA, 18:2n-6) and $\alpha$-linolenic acid (ALA, $18: 3 n$-3) at 4.04 (D2) and 0.54 (D3), respectively. At the end of feeding trial, the growth performance of D2 and D3 groups under all salinity treatments was as good as that of D1 group, which indicates that the GIFT juveniles may convert dietary LA and ALA into LC-PUFA to meet the requirement of essential fatty acids for normal growth and physiology. When fed the same diets, GIFT at $12 \mathrm{ppt}$ had a better growth performance coupled with a higher liver and muscle arachidonic acid content than those in freshwater. Furthermore, brackish water (24 ppt) significantly promoted the mRNA levels of elongase 5 of very long-chain fatty acids (elovl5) and peroxisome proliferator-activated receptor $\alpha$ (ppar $\alpha)$ in liver, when compared with freshwater. These results suggest that the GIFT may display better growth performance together with a relatively higher endogenous LC-PUFA biosynthetic ability under brackish water (12 and $24 \mathrm{ppt}$ ), probably through improving the expression of elovl5 and ppara in liver.

\section{Key words: Genetically improved farmed tilapia: Salinity: Growth performance: Long-chain PUFA biosynthesis}

Long-chain PUFA (LC-PUFA), including arachidonic acid (ARA), EPA and DHA, mediate lipid metabolism, participate in immune reactions and comprise the biomembranes ${ }^{(1,2)}$. Moreover, the so-called ' $n$-3' LC-PUFA such as EPA and DHA are necessary for building the phospholipids of biomembranes, with $n-3$ LC-PUFA supplements in diets demonstrated to be effective in the prevention/treatment of obesity, the metabolic syndrome and CVD in human ${ }^{(3)}$. Fish are major sources of $n$-3 LC-PUFA in human diets, which therefore drives the flourishing and development of the aquaculture industry. Traditionally, high levels of fishmeal and fish oils (FO) are included in aquafeeds to deliver high $n$-3 LC-PUFA contents in farmed fish. Because the illogicality between the increasing demand and deficiency of FO is becoming more and more serious, considerable attention is focused on investigating the sustainable alternative to FO, not to reduce the LC-PUFA content of farmed fish. Vegetable oils (VO) rich in C18 PUFA including $\alpha$-linolenic acid (ALA, 18:3n-3) and linoleic acid (LA, 18:2n-6) have been regarded as the ideal alternative to $\mathrm{FO}$ in aquafeeds ${ }^{(2)}$. Many researchers are devoting their attention to improve the substitute ratio with $\mathrm{VO}$ in aquafeeds, not to impair the nutritional quality of farmed fish.

It is generally accepted that mammals can convert dietary ALA (18:3n-3) and LA (18:2n-6) into LC-PUFA through a series of fatty acid desaturation and carbon chain extension reactions, in which key enzymes involve fatty acyl desaturases (Fads: $\Delta 6$ Fads and $\Delta 5$ Fads) and elongases (elongases of very long-chain fatty acids (Elovl): ELOVL5, ELOVL4 and ELOVL2) ${ }^{(1-6)}$. However, the LC-PUFA bioconversion ability of fish varies among species and depends upon the complement and function of Fads and Elovl in fish species ${ }^{(4,7)}$. All the cloned teleost fads genes belong to the mammalian fads2-type, which shows $\Delta 6$ desaturase activity in most teleosts, monofunctional

\footnotetext{
Abbreviations: ALA, $\alpha$-linolenic acid; ARA, arachidonic acid; Elovl, elongase of very long-chain fatty acids; fads, fatty acyl desaturase; FCR, feed conversion ratio; FO, fish oil; GIFT, genetically improved farmed tilapia; HNF $4 \alpha$, hepatocyte nuclear factor $4 \alpha$; LA, linoleic acid; LC-PUFA, long-chain PUFA; LXR, liver X receptor; ppt, parts per thousand; SGR, specific growth rate; SREBP-1, sterol regulatory element-binding protein-1; VO, vegetable oil; WGR, weight gain rate.
}

* Corresponding author: Professor Y. Li, email yyli16@scau.edu.cn

$\dagger$ These authors contributed equally to the study. 
$\Delta 5$ desaturases or bifunctional $\Delta 6 / \Delta 5$ desaturases in freshwater and salmonid species as well as $\Delta 4$ desaturase activity in some teleost fish ${ }^{(4-8)}$. The gene coding Elovl5 has been found in all the fish that have so far been examined ${ }^{(2,7)}$. Historically, it has been recognised that freshwater and salmonid species can convert dietary ALA and LA into LC-PUFA, similar to the mammals, while marine fish typically have a low capability or inability to transform C18 precursors into LC-PUFA, due to the loss-of-function mutations of $\Delta 5$ Fads 2 or Elovl $2^{(2,4,7,8,9)}$. So investigation of upregulation of the expression of the desaturases and elongase to improve the endogenous LC-PUFA biosynthetic ability of fish is attracting more attention. At a molecular level, the expression of desaturases and elongases is reported to be modulated at the transcriptional level by key transcription factors such as PPAR, sterol regulatory element-binding protein-1 (SREBP-1), liver X receptor (LXR) and hepatocyte nuclear factor $4 \alpha(\mathrm{HNF} 4 \alpha)$ in vertebrates $^{(10-15)}$. For example, the expression of the $\Delta 5$ and $\Delta 6$ desaturases and Elovl5 is stimulated to promote the production of LC-PUFA through the LXR $\alpha$-SREBP-1 pathway in mammals and fish ${ }^{(10,11)}$, while PPAR are reported to stimulate human SREBP-1, either by directly binding to the PPAR response elements on the promoter or via cross-regulation with the LXR in mice $^{(12,13)}$. Recently, we demonstrated that HNF $4 \alpha$ might play a crucial role in the upregulation of $\Delta 5 / \Delta 6$ fads 2 and $\Delta 4$ fads 2 in the herbivorous marine fish Siganus canaliculatus ${ }^{(14,15)}$.

Moreover, the endogenous LC-PUFA biosynthetic capacity of fish may be influenced by environmental salinity ${ }^{(2)}$. Our previous study found that low salinity could enhance the mRNA expression of key enzyme genes including $\Delta 5 / \Delta 6$ fads $2, \Delta 4$ fads 2 and elovl5 and the related transcription factor genes such as ppars, srebp- 1 and $h n f 4 \alpha$ as well as the ability of production of LC-PUFA in the rabbitfish $S$. canaliculatus ${ }^{(14-19)}$. A similar phenomenon was observed in the red sea bream Pagrus major with higher fads 2 expression and liver EPA and DHA contents in 15\%o (parts per thousand; ppt) water compared to $33 \mathrm{ppt}$ water ${ }^{(20)}$. It is indicated that water salinity might affect the LC-PUFA bioconversion capacity from $\mathrm{C} 18$ precursors by regulating the expression of desaturases and elongases in fish. Moreover, the optimal dietary ALA:LA ratio of 1.93 is proposed for $S$. canaliculatus juveniles $^{(21)}$. However, the effect of environmental salinity on endogenous LC-PUFA biosynthesis in fish varies among different species. Contrary to what is observed in $S$. canaliculatus and $P$. major, the muscle EPA and DHA contents in euryhalinous Alosa sapidissima increased with an increase in salinity $^{(22)}$. Similarly, seawater environment also improves the accumulation of EPA and $n$-3 PUFA in rainbow trout Oncorbynchus mykiss liver ${ }^{\text {(23) }}$ as well as the accumulation of DHA and EPA in muscle and liver of Japanese sea bass (Lateolabrax japonicus $)^{(24)}$. The different and varying effects of environmental salinity on LC-PUFA biosynthesis of fish in various species need further studies in euryhaline commercial fish.

Nile tilapia (Oreochromis niloticus), a euryhaline and omnivorous fish with extremely strong fertility and viability ${ }^{(25)}$, is one of the fish species with maximum aquaculture productions. It is estimated that the global tilapia yields will reach 7.5 million tons in $2030^{(26)}$. Previous studies have demonstrated that Nile tilapia can convert C18 PUFA precursors into LC-PUFA ${ }^{(27,28)}$ and show the best growth performance in freshwater ${ }^{(29)}$. The genetically improved farmed tilapia
(GIFT) strain was established in Malaysia in 2002 through twelve generations of natural genetic selection of $O$. niloticus for the improved growth performance. It has become one of the successfully introduced farmed Nile tilapia that flourishes in China. Previous studies have shown that GIFT exhibits a higher LC-PUFA bioconversion ability than the red hybrid tilapia (Oreochromis sp.), another farmed tilapia species, which is preferred by consumers due to its red colouration $^{(30)}$. However, the LC-PUFA bioconversion ability of GIFT in different salinities has not been studied in detail. In the present study, three formulated feeds with (FO as lipid source) or without (VO blends as lipid source) LC-PUFA were used to feed juvenile GIFT in freshwater ( $0 \mathrm{ppt}$ ) and brackish water (12 and $24 \mathrm{ppt}$ ) for 8 weeks. The aim was to investigate the capacity of utilising 18C PUFA precursors (ALA and LA) by GIFT in different salinities, and the proper dietary lipid source, by comparing the growth performance, tissue fatty acid composition, and mRNA expression levels of related genes to LC-PUFA synthesis among different treatments.

\section{Methods \\ Experimental diets}

Casein, soyabean meal and gelatin were used as protein sources; rapeseed oil (RO), perilla oil (PO), soyabean oil (SBO) or FO were used as lipid sources. A total of three isonitrogenous (32\%)

Table 1. Ingredients and proximate composition ( $\mathrm{g} / \mathrm{kg}$ diet) of the experimental diets

\begin{tabular}{|c|c|c|c|}
\hline \multirow[b]{2}{*}{ Ingredients } & \multicolumn{3}{|c|}{ Experimental diets* } \\
\hline & D1 & D2 & D3 \\
\hline Caseint & 240 & 240 & 240 \\
\hline Soyabean meal‡ & 120 & 120 & 120 \\
\hline Gelatin & 60 & 60 & 60 \\
\hline Fish oil§ & 80 & - & - \\
\hline Rapeseed oilll & - & 40 & 40 \\
\hline Soyabean oilף & - & 40 & - \\
\hline Perilla oil ${ }^{\star *}$ & - & - & 40 \\
\hline Tapioca starch & 345 & 345 & 345 \\
\hline Alpha-cellulose & 100 & 100 & 100 \\
\hline Monocalcium phosphate & 20 & 20 & 20 \\
\hline Vitamin premix†† & 10 & 10 & 10 \\
\hline Mineral premixł‡ & 20 & 20 & 20 \\
\hline Betaine & 4 & 4 & 4 \\
\hline Choline chloride & 1 & 1 & 1 \\
\hline \multicolumn{4}{|l|}{ Nutrition component } \\
\hline Crude protein & 320.6 & $317 \cdot 8$ & $312 \cdot 1$ \\
\hline Crude lipid & $75 \cdot 5$ & $72 \cdot 2$ & 73.1 \\
\hline Ash & $32 \cdot 3$ & $34 \cdot 1$ & 31.7 \\
\hline
\end{tabular}

* Experimental diets nomenclature: D1, fish oil; D2, soyabean and rapeseed oil; D3, perilla and rapeseed oil.

† Casein: protein content, $80 \%$.

‡ Soyabean meal: protein content, $48 \%$.

$\S$ Peruvian fish oil: $a$-linolenic acid content, $0.6 \%$; linoleic acid content, $1.3 \%$.

॥ Rapeseed oil: $a$-linolenic acid content, $12 \%$; linoleic acid content, $20 \%$.

I Soyabean oil: $a$-linolenic acid content, $7 \%$; linoleic acid content, $61 \%$.

** Perilla oil: $a$-linolenic acid content, $67 \%$; linoleic acid content, $14 \%$.

†† The amount of vitamin per kg of premix was as follows: vitamin A, $3.3 \mathrm{mg}$; vitamin $\mathrm{D}_{3}, 0.08 \mathrm{mg}$; vitamin $\mathrm{E}, 307 \mathrm{mg}$; vitamin $\mathrm{K}_{3}, 1000 \mathrm{mg}$; vitamin $\mathrm{B}_{1}, 1500 \mathrm{mg}$; vitamin $\mathrm{B}_{2}, 2800 \mathrm{mg}$; vitamin $\mathrm{B}_{6}, 1000 \mathrm{mg}$; vitamin $\mathrm{B}_{12}, 8 \mathrm{mg}$; D-calcium pantothenate, $2000 \mathrm{mg}$; nicotinic acid, $7800 \mathrm{mg}$; biotin, $8 \mathrm{mg}$; folic acid, $400 \mathrm{mg}$; inositol, $12800 \mathrm{mg}$; stable vitamin C, $20000 \mathrm{mg}$.

㧊 The amount of ingredients per kg of premix was as follows: Fe, $10 \mathrm{~g} ; \mathrm{Zn}, 3.2 \mathrm{~g} ; \mathrm{Mn}$, $3 \mathrm{~g}$; Co, $52 \mathrm{mg}$; iodine, $65 \mathrm{mg}$; Se, $15 \mathrm{mg}$. 
Table 2. Fatty acid composition of the experimental diets (\% total fatty acids) for genetically improved farmed tilapia (Oreochromis niloticus)

\begin{tabular}{|c|c|c|c|}
\hline \multirow[b]{2}{*}{ Fatty acids } & \multicolumn{3}{|c|}{ Experimental diets } \\
\hline & D1 & D2 & D3 \\
\hline $14: 0$ & $8 \cdot 34$ & 0.89 & 1.08 \\
\hline $16: 0$ & 24.82 & $10 \cdot 76$ & 9.81 \\
\hline $16: 1 n-7$ & $5 \cdot 26$ & 0.34 & 0.36 \\
\hline $18: 0$ & $6 \cdot 24$ & 0.47 & 0.42 \\
\hline $18: 1 n-9$ & 11.49 & 41.49 & $36 \cdot 64$ \\
\hline $18: 2 n-6$ & 5.59 & 33.42 & $16 \cdot 77$ \\
\hline $18: 3 n-3$ & 2.65 & 8.27 & 30.97 \\
\hline $18: 3 n-6$ & 0.40 & $-^{\star}$ & - \\
\hline $20: 1 n-9$ & 1.98 & $2 \cdot 11$ & 1.98 \\
\hline $20: 2 n-6$ & $2 \cdot 34$ & - & - \\
\hline $20: 3 n-3$ & $2 \cdot 66$ & - & - \\
\hline $20: 3 n-6$ & 0.26 & - & - \\
\hline $20: 4 n-3$ & 0.92 & - & - \\
\hline $20: 4 n-6$ (ARA) & 0.62 & - & - \\
\hline $20: 5 n-3$ (EPA) & $9 \cdot 16$ & - & - \\
\hline $22: 5 n-3$ (DPA) & 0.75 & - & - \\
\hline $22: 6 n-3(\mathrm{DHA})$ & 14.53 & - & - \\
\hline SAF & 39.40 & $12 \cdot 12$ & 11.31 \\
\hline MUFA & 18.73 & 43.94 & 38.98 \\
\hline$n-6$ PUFA & $9 \cdot 21$ & 33.42 & $16 \cdot 77$ \\
\hline$n-3$ PUFA & 30.58 & 8.27 & 30.97 \\
\hline LA:ALA & $2 \cdot 11$ & 4.04 & 0.54 \\
\hline
\end{tabular}

ARA, arachidonic acid; DPA, docosapentaenoic acid.

* Not detected.

and isolipidic (8\%) diets were made using different dietary lipid sources, including the control diet (D1) using FO; a high-LA diet (D2) using $\mathrm{SBO}: \mathrm{RO}=1: 1$ (LA:ALA ratio of 4.04); a high-ALA diet (D3) using PO:RO=1:1 (LA:ALA ratio of 0.54) (Tables 1 and 2). Soyabean meal and gelatin were finely ground through 60 mesh using a laboratory mill. Small total amounts of the powdered ingredients were first mixed together in a laboratory feed mixer and then mixed thoroughly with the other ingredients. Next, the dietary powder was mixed and homogenised with oil and distilled water. The mixture was then transformed into hard pellets by extrusion at $90^{\circ} \mathrm{C}$ in a laboratory feed-pelletiser equipped with a $4 \mathrm{~mm}$ die. The wet pellets were air-dried at room temperature, sealed and stored at $-20^{\circ} \mathrm{C}$ before feeding.

\section{Fish husbandry and sample collection}

Juvenile GIFT (average weight $4 \mathrm{~g}$ ) were obtained from a local freshwater aquaculture farm (Chaozhou, China) and transferred to three indoor circular tanks $\left(6 \mathrm{~m}^{3}\right)$ with 1000 individuals per tank in Nan Ao Marine Biology Station of Shantou University. After indoor acclimation for 2 weeks, healthy juveniles of similar sizes were selected for salinity acclimation. In two rearing tanks $\left(6 \mathrm{~m}^{3}\right)$, the juveniles were acclimated from freshwater to 12 and $24 \%$ salinity, respectively, increasing the salinity by adding filtered seawater at $4 \%$ salinity every $2 \mathrm{~d}$ and then maintained for another 2 weeks by replacing with the same salinity water from the reservoir tanks. In the freshwater tank $\left(6 \mathrm{~m}^{3}\right)$, the juveniles were unceasingly maintained in aerated freshwater. During the husbandry periods and salinity acclimation, the juveniles were fed commercial fish pellets (Guangzhou Hailong Feed Corporation Limited) three times a day $(07.30,11.30$ and 16.30 hours) at $3 \%$ of body weight.
Before the start of the normal growth experiment, fish with similar sizes were transferred to the 500 litres indoor conical aquaria $(90 \mathrm{~cm} \Phi, 60 \mathrm{~cm}$ depth) equipped with internal biological filters for a further 2-week acclimation. During this period, the fish were fed a mixture of three experimental diets (D1-D3, each with equal proportions). In the following 8 weeks, the normal feeding trial was performed in the 500 litres aquariums with D1-D3 diets at 0, 12 and $24 \mathrm{ppt}$, respectively. Each dietary group was performed at the three salinities, and each treatment was run in three replicate aquariums, with a total of twenty-seven aquariums. Each aquarium was allocated with twenty individuals, which were separately weighed after anaesthesia in $0.02 \%$ 2-phenoxyethanol. During the growth experiment, fish were fed the experimental diet three times a day at $3 \%$ of body weight. Each time the fish in all the twentyseven experimental aquariums were fed in order for three rounds, and the uneaten feeds were collected timely to record the daily fed amounts. The water quality in aquariums was maintained by replacing half volume of the aquarium water every $2 \mathrm{~d}$, while the faecal matter was removed through the bottom auto-discharge device of the conical aquarium. The dissolved $\mathrm{O}_{2}$ was above $6 \mathrm{mg} / \mathrm{l}$, and the temperature was maintained at $25-27^{\circ} \mathrm{C}$.

At the end of the growth experiment, all fish were starved for $24 \mathrm{~h}$, anaesthetised by $0.02 \%$ 2-phenoxyethanol and weighed individually. From each aquarium, two whole fish were collected for proximate composition analysis and another three fish were dissected to collect liver and muscle tissues. All the whole-body fish and tissues were flash-frozen in liquid $\mathrm{N}_{2}$ and stored at $-80^{\circ} \mathrm{C}$ until use.

The weight gain rate (WGR), specific growth rate (SGR) and feed conversion ratio (FCR) of the fish, and the feed intake per fish were calculated according to the following formulae:

$$
\begin{aligned}
\operatorname{WGR}(\%) & =100 \times\left(W_{\mathrm{f}}-W_{\mathrm{i}}\right) / W_{\mathrm{i}} \\
\operatorname{SGR}(\% \mathrm{~d}) & =100 \times\left(\ln W_{\mathrm{f}}-\ln W_{\mathrm{i}}\right) / d \\
\mathrm{FCR} & =W_{\mathrm{d}} /\left(W_{\mathrm{f}}-W_{\mathrm{i}}\right)
\end{aligned}
$$

Feed intake per fish $=$ feed intake $/$ number of individuals

In the above formulae, $W_{\mathrm{f}}$ and $W_{\mathrm{i}}$ are the final and initial body weight, respectively, $d$ represents the experimental days, while $W_{\mathrm{d}}$ the dry amount of diet fed by fish.

\section{Proximate composition analysis}

The methods used for proximate composition analysis of experimental diets and whole-body fish were as described previously in our laboratory ${ }^{(1)}$. Briefly, moisture was determined by drying in an oven at $80^{\circ} \mathrm{C}$ to constant weight. Crude protein content was calculated by determining the total $\mathrm{N}$ content using the Kjeldahl methods. Crude lipid content was measured by the Soxhlet extraction. Ash content was determined through combustion in a muffle furnace at $550^{\circ} \mathrm{C}$ for $8 \mathrm{~h}$. Duplicate analyses were conducted for each sample. 


\section{Fatty acid analysis}

Freeze-dried samples of experimental diets and fish tissues were prepared for lipid extractions with chloroform-methanol $(2: 1, \mathrm{v} / \mathrm{v})$ containing $0 \cdot 01 \%$ butylated hydroxytoluene. The lipid extracts were esterified into methyl esters by boron trifluoridemethanol complex catalysed transesterification (Sigma-Aldrich). Fatty acid methyl esters were separated using a GC (GC-2010; Shimadzu) equipped with an auto-sampler and a $\mathrm{H}_{2}$ flame ionisation detector. The detailed GC parameters were as described previously ${ }^{(16)}$. Fatty acids were identified individually by comparison with known commercial standards (Sigma-Aldrich) and quantified with CLASS-GC10 GC workstation (Shimadzu).

\section{mRNA expression of key genes related to long-chain PUFA biosynthesis}

Total RNA was extracted from GIFT liver tissue using the TriPure Isolation Reagent (Roche). The quality and concentration of the RNA extracts were measured by agarose gel electrophoresis and spectrophotometry (Nanodrop 2000; Thermo Scientific). Next, $1 \mu \mathrm{g}$ of total RNA was reverse transcribed into complementary DNA (cDNA) using the FastQuant ${ }^{\circledR}$ RT kit (Tiangen) with a genomic DNA elimination reaction. The mRNA expression of the genes most related to LC-PUFA biosynthesis in GIFT liver was determined by real-time quantitative PCR (qPCR) using $\beta$-actin as a reference gene. Specific primers were designed based on the published sequences of Nile tilapia $(O \text {. niloticus })^{(31,32)}$ : the key enzyme genes: $\Delta 5 / \Delta 6$ fads 2 (AB069727), $\Delta 4$ fads2 (XM003440472), elovl5 (AY170326); the related transcription factor genes: ppara (KF871430), srebp-1 (XM005457771), lxr (XM005455714), bnf4 $\alpha$ (XM003457051); the housekeeping gene: $\beta$-actin (EU887951) (Table 3). The mRNA expression of each gene was normalised relative to the $\beta$-actin mRNA and determined by the comparative threshold cycle method $^{(33)}$. The qPCR was performed on a Lightcycler 480 system (Roche) in a total reaction volume of $20 \mu \mathrm{l}$ containing $10 \mu \mathrm{l}$ of SYBR Green Supermix (Roche), $1 \mu \mathrm{l}$ of each primer $(10 \mu \mathrm{m}), 6 \mu \mathrm{ddH}_{2} \mathrm{O}$ and $2 \mu \mathrm{l}$ of cDNA $(10 \mathrm{ng} / \mu \mathrm{l})$. The qPCR programme consisted of an initial
DNA denaturation step at $94^{\circ} \mathrm{C}$ for $5 \mathrm{~min}$, followed by forty-five cycles at $95^{\circ} \mathrm{C}$ for $10 \mathrm{~s}$, annealing $60^{\circ} \mathrm{C}$ for $20 \mathrm{~s}$, extension $72^{\circ} \mathrm{C}$ for $20 \mathrm{~s}$, and with a final extension step at $95^{\circ} \mathrm{C}$ for $5 \mathrm{~s}, 65^{\circ} \mathrm{C}$ for $60 \mathrm{~s}$ and $40^{\circ} \mathrm{C}$ for $10 \mathrm{~s}$. Triplicate reactions were performed for each sample.

\section{Statistical analysis}

All data are presented as means with their standard errors. The differences among treatments were analysed by two-way ANOVA followed by Tukey's multiple comparison test, where the diet (D1, D2 and D3) and water salinity (0, 12 and 24ppt) were determined as the first and second independent variables, respectively (OriginPro 75; OriginLab). The significant level was considered at $P<0 \cdot 05$.

\section{Results \\ Growth performance and proximate composition of genetically improved farmed tilapia}

In the experimental trials, all treatment groups had survival rates not $<95 \%$ (Table 4). The two-way ANOVA showed that the WGR, SGR and FCR in GIFT were not significantly affected by the dietary lipid sources $(P>0.05)$ but were impacted by water salinity $(P<0.05)$ (Table 4). When fed the same diets, GIFT maintained at 12 ppt exhibited the highest WGR and SGR, which were significantly higher than the fish maintained at 0 and $24 \mathrm{ppt}(P<0.05)$. These fish also had the lowest FCR, which was significantly lower than those maintained in 0 ppt water $(P<0 \cdot 05)$. Under the same salinity, the D2 group had the best growth performance, although there was no significant difference with the other two dietary groups (D1 and D3 groups) $(P>0 \cdot 05)$. Besides, the proximate composition of fish showed no significance among the different salinity treatments $(P>0.05)$, except the crude protein content that was significantly affected by the dietary lipid sources $(P<0.05)$ (Table 5), with D2 group exhibiting a higher crude protein content than D1 group $(P<0 \cdot 05)$.

Table 3. Primers used for determination of the mRNA expression of the key enzyme and transcription factor genes by real-time quantitative PCR in genetically improved farmed tilapia (Oreochromis niloticus)

\begin{tabular}{|c|c|c|c|}
\hline Gene & Primers & Sequence $5^{\prime}-3^{\prime}$ & GenBank accession no. \\
\hline$\beta$-Actin & $\begin{array}{l}\beta \text {-Actin-S } \\
\beta \text {-Actin-A }\end{array}$ & $\begin{array}{l}\text { CAGGGAGAAGATGACCCAGA } \\
\text { CAGGGCATAACCCTCGTAGA }\end{array}$ & EU887951 \\
\hline$\Delta 6 / \Delta 5$ fads2 & $\begin{array}{l}\Delta 6 / \Delta 5 \text { Fads2-S } \\
\Delta 6 / \Delta 5 \text { Fads2-A }\end{array}$ & $\begin{array}{l}\text { GTGGATCTGGCTTGGTTCAT } \\
\text { CCAGTCCCTGTGCTTTTCAT }\end{array}$ & АВ069727 \\
\hline$\Delta 4$ fads2 & $\begin{array}{l}\Delta 4 \text { Fads2-S } \\
\Delta 4 \text { Fads2-A }\end{array}$ & $\begin{array}{l}\text { CTTACTGTGCTCGGTGATT } \\
\text { GGTCCTTGCTGAAGATGTT }\end{array}$ & XM003440472 \\
\hline elovl5 & $\begin{array}{l}\text { Elov15-S } \\
\text { Elov15-A }\end{array}$ & $\begin{array}{l}\text { GCCATACCTTTGGTGGAAGA } \\
\text { AGGGAGCTGTTCTGTGGATG }\end{array}$ & AY170326 \\
\hline srebp-1 & $\begin{array}{l}\text { SREBP-1-S } \\
\text { SREBP-1-A }\end{array}$ & $\begin{array}{l}\text { TGGAGACATCGCAAACAGG } \\
\text { TGGAGGCAGAATCTTAGCA }\end{array}$ & XM005457771 \\
\hline ppara & $\begin{array}{l}\text { PPAR } a-S \\
\text { PPAR } a-A\end{array}$ & $\begin{array}{l}\text { TGGTTCGGGGTCCAATAG } \\
\text { GCAGTTCCGCTCACACTTAT }\end{array}$ & KF871430 \\
\hline Ixr & $\begin{array}{l}\text { LXR-S } \\
\text { LXR-A }\end{array}$ & $\begin{array}{l}\text { GTAAGGTGTTTGATGGGGC } \\
\text { ATTATGAGGGGGGACGG }\end{array}$ & XM005455714 \\
\hline$h n f 4 a$ & $\begin{array}{l}\text { HNF4a-S } \\
\text { HNF4a-A }\end{array}$ & $\begin{array}{l}\text { AACGAGACAGAATCAGCACC } \\
\text { CCACTCCACTAAGACCAACAG }\end{array}$ & XM003457051 \\
\hline
\end{tabular}


Table 4. Growth performance and feeding efficiency of genetically improved farmed tilapia (Oreochromis niloticus) reared at 0,12 and $24 \%$ (parts per thousand; ppt) with the experimental diets for 8 weeks

(Mean values with their standard errors, $n$ 3)

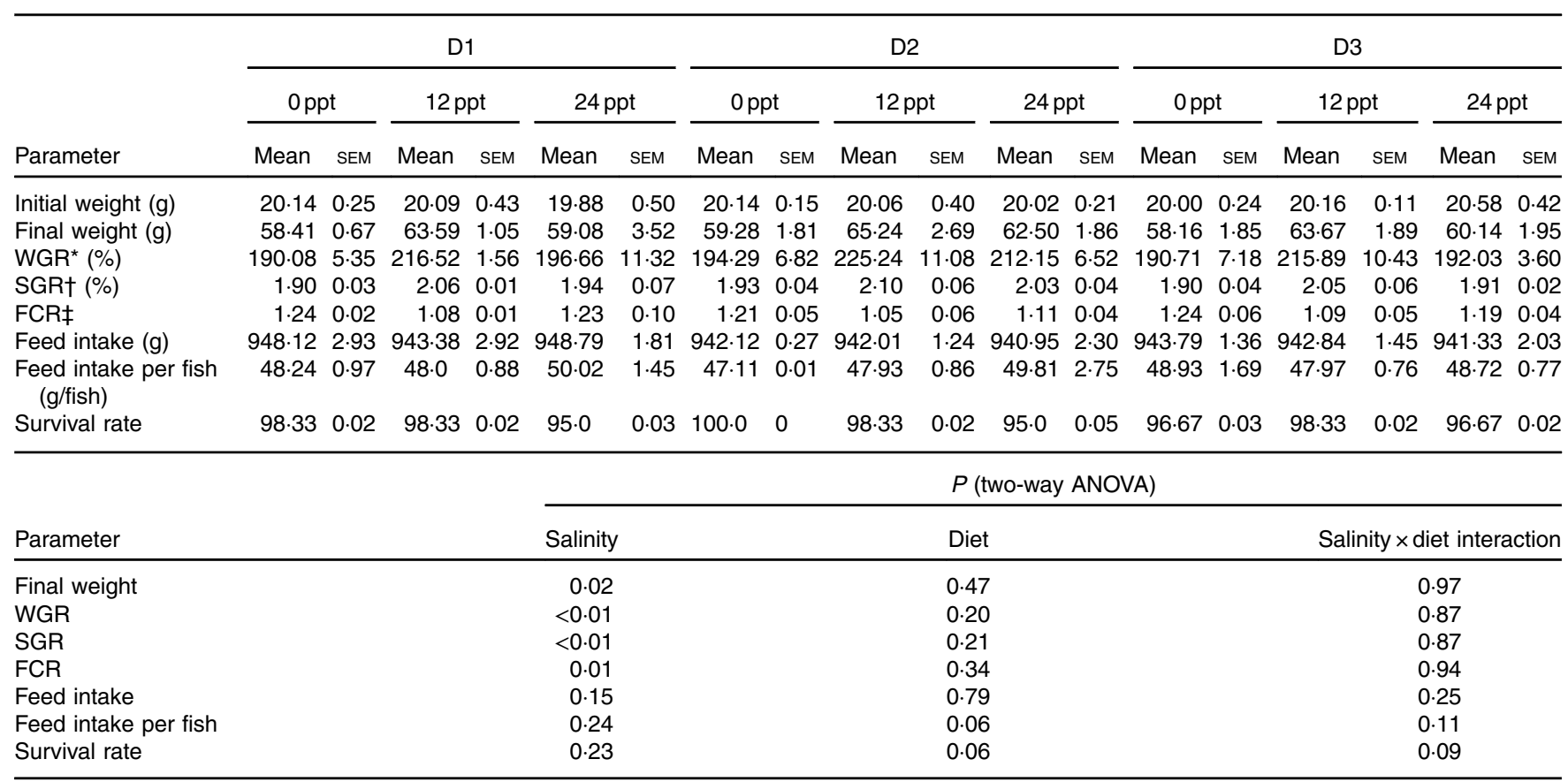

ppt, Parts per thousand; WGR, weight gain rate; SGR, specific growth rate; FCR, feed conversion ratio

${ }^{*}$ WGR $=100 \times$ (final fish weight-initial fish weight)/initial fish weight.

$\dagger \mathrm{SGR}=100 \times($ In (final mean weight) $-\ln$ (initial mean weight) $) / \mathrm{d}$ fed

$\ddagger \mathrm{FCR}=$ dry amount of feed intake/(final fish weight-initial fish weight).

Table 5. Whole-body proximate composition of genetically improved farmed tilapia (Oreochromis niloticus) at the end of the growth experiment (Mean values with their standard errors, $n$ 3)

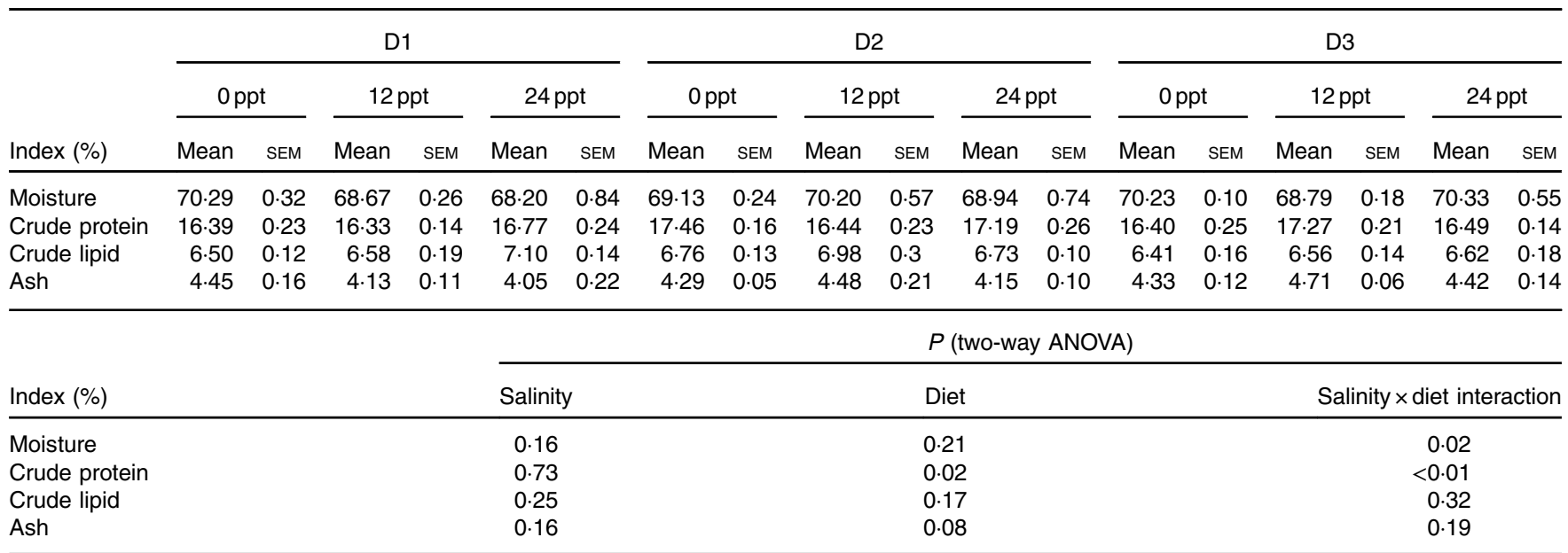

ppt, Parts per thousand.

Fatty acid composition of tissues in the genetically improved farmed tilapia

The fatty acid composition in muscle of GIFT is shown in Table 6. Two-way ANOVA showed that almost all the muscle fatty acid contents were significantly affected by the dietary lipid source $(P<0 \cdot 05)$, and only a few PUFA such as C18:2n-6, C20:4n-6, C20:4n-3 and C22:5n-3 were significantly affected by water salinity $(P<0.05)$. When fed the same diets, the GIFT exhibited a higher muscle ARA $(20: 4 n-6)$ content in brackish water (12 and
$24 \mathrm{ppt})$ than in freshwater $(P<0 \cdot 05)$. Under the same water salinity, the muscle EPA (20:5n-3) and DHA (22:6n-3) contents of the two $\mathrm{VO}$ groups (D2 and D3 groups) were significantly lower than the FO group (D1 group) $(P<0 \cdot 05)$. The muscle ARA content of the D2 group was significantly higher than the D3 group $(P<0.05)$ but showed no significance with the D1 group $(P>0 \cdot 05)$.

The fatty acid composition in the liver of GIFT is shown in Table 7. The results showed that the PUFA (ALA, LA, ARA, EPA and DHA) were significantly affected by the dietary lipid sources 
Table 6. Muscle fatty acid composition of genetically improved farmed tilapia (Oreochromis niloticus) fed with diets D1-D3 at different ambient salinities for 8 weeks

(Mean values with their standard errors, $n 3$ )

\begin{tabular}{|c|c|c|c|c|c|c|c|c|c|c|c|c|c|c|c|c|c|c|}
\hline \multirow{3}{*}{$\frac{\text { Main }}{\text { Fatty acids }}$} & \multicolumn{6}{|c|}{ D1 } & \multicolumn{6}{|c|}{ D2 } & \multicolumn{6}{|c|}{ D3 } \\
\hline & \multicolumn{2}{|c|}{$0 \mathrm{ppt}$} & \multicolumn{2}{|c|}{$12 \mathrm{ppt}$} & \multicolumn{2}{|c|}{$24 \mathrm{ppt}$} & \multicolumn{2}{|c|}{$0 \mathrm{ppt}$} & \multicolumn{2}{|c|}{$12 \mathrm{ppt}$} & \multicolumn{2}{|c|}{$24 \mathrm{ppt}$} & \multicolumn{2}{|c|}{$0 \mathrm{ppt}$} & \multicolumn{2}{|c|}{$12 \mathrm{ppt}$} & \multicolumn{2}{|c|}{$24 \mathrm{ppt}$} \\
\hline & Mean & SEM & Mean & SEM & Mean & SEM & Mean & SEM & Mean & SEM & Mean & SEM & Mean & SEM & Mean & SEM & Mean & SEM \\
\hline$: 1 n-9$ & 59 & 0.99 & $16 \cdot 83$ & $1 \cdot 14$ & 5.41 & 0.25 & 63 & 1.49 & 78 & 0.77 & 28.02 & 2.04 & $27 \cdot 28$ & 1.69 & 32.48 & 0.99 & 31.54 & 1.44 \\
\hline $18: 2 n-6$ & 5.08 & 0.19 & 4.72 & 0.12 & 4.46 & 0.46 & 13.72 & 0.24 & $10 \cdot 00$ & 0.66 & 14.09 & 0.61 & $6 \cdot 31$ & 0.36 & 4.81 & 0.66 & $6 \cdot 64$ & 1.4 \\
\hline $18: 3 n-3$ & 0.50 & 0.01 & 0.51 & 0.01 & 0.44 & 0.04 & 1.21 & 0.07 & $1 \cdot 20$ & 0.08 & $2 \cdot 31$ & 0.13 & $8 \cdot 67$ & 0.29 & 6.96 & 0.89 & 8.92 & 1.65 \\
\hline $20: 2 n-6$ & 0.52 & 0.04 & 0.50 & 0.12 & 0.48 & 0.04 & 1.23 & 0.06 & 0.86 & $0 \cdot 19$ & 0.89 & 0.11 & 0.72 & 0.05 & 0.73 & 0.24 & 0.64 & 0.10 \\
\hline $20: 4 n-3$ & 3.54 & 0.25 & 3.76 & 0.21 & 3.42 & 0.11 & 3.65 & 0.31 & 1.37 & 0.11 & 2.94 & 0.08 & $2 \cdot 50$ & 0.24 & $1 \cdot 71$ & 0.59 & 1.53 & 0.2 \\
\hline $20: 4 n-6$ & 1.71 & 0.06 & $2 \cdot 15$ & 0.07 & $2 \cdot 67$ & 0.1 & 1.75 & 0.05 & $2 \cdot 62$ & 0.05 & $2 \cdot 42$ & 0.06 & 0.80 & 0.03 & 1.78 & 0.12 & 1.44 & 0.1 \\
\hline $20: 5 n-3$ (EPA) & 3.17 & 0.20 & 3.82 & 0.17 & 3.81 & 0.13 & 1.50 & 0.13 & 1.05 & 0.09 & 1.55 & 0.12 & 2.51 & 0.21 & 1.67 & 0.08 & 2.07 & 0.4 \\
\hline $22: 5 n-3$ (DPA) & 1.51 & 0.09 & 1.49 & 0.09 & 1.41 & 0.07 & 4.85 & 0.41 & 2.06 & 0.01 & 2.85 & 0.12 & 1.58 & 0.14 & 1.40 & 0.13 & 1.63 & 0.44 \\
\hline $22: 6 n-3$ (DHA) & 19.83 & 1.48 & 19.66 & 1.94 & $20 \cdot 48$ & 0.06 & $7 \cdot 37$ & 0.83 & $7 \cdot 89$ & 0.31 & 7.79 & 1.03 & $10 \cdot 47$ & 0.88 & $10 \cdot 08$ & 0.88 & 9.23 & 0.42 \\
\hline SFA & 35.99 & 1.03 & 37.63 & 1.27 & $38 \cdot 17$ & 0.88 & $30 \cdot 38$ & 0.93 & 31.55 & $1 \cdot 13$ & 30.68 & $1 \cdot 13$ & $30 \cdot 84$ & 0.51 & 30.12 & 0.68 & $28 \cdot 37$ & 0.6 \\
\hline MUFA & $26 \cdot 49$ & 0.58 & $24 \cdot 88$ & $1 \cdot 74$ & $23 \cdot 12$ & 0.12 & 32.46 & 1.47 & $41 \cdot 12$ & 0.92 & 33.70 & $2 \cdot 14$ & 33.08 & $1 \cdot 84$ & 38.49 & 1.22 & $37 \cdot 15$ & 1.7 \\
\hline$n-6$ PUFA & 7.31 & 0.17 & $7 \cdot 67$ & 0.16 & $7 \cdot 61$ & 0.18 & $16 \cdot 71$ & 0.14 & 13.48 & 0.24 & 17.40 & 0.43 & 7.84 & 0.20 & $7 \cdot 32$ & 0.23 & 8.72 & 0.46 \\
\hline$n-3$ PUFA & 28.55 & 1.61 & $30 \cdot 25$ & 1.33 & 29.57 & 0.18 & 18.59 & 1.45 & 13.56 & 0.28 & 17.44 & 1.71 & $25 \cdot 73$ & 1.45 & 21.83 & 0.80 & 23.38 & $2 \cdot 28$ \\
\hline $\mathrm{DHA}+\mathrm{EPA}$ & 23.00 & 0.29 & 23.48 & 0.17 & $24 \cdot 29$ & 0.18 & 8.87 & $0 \cdot 18$ & 8.94 & 0.29 & $9 \cdot 34$ & 0.28 & 12.98 & 0.25 & 11.75 & 0.25 & 11.30 & 0.25 \\
\hline
\end{tabular}

\begin{tabular}{lccr}
\hline & & $P$ (two-way ANOVA) & \\
\cline { 2 - 4 } Fatty acid & Salinity & Diet & Salinity $\times$ diet interaction \\
\hline $18: 1 n-9$ & 0.01 & $<0.01$ & 0.01 \\
$18: 2 n-6$ & $<0.01$ & $<0.01$ & 0.01 \\
$18: 3 n-3$ & 0.18 & $<0.01$ & 0.49 \\
$20: 2 n-6$ & 0.3 & $<0.01$ & 0.54 \\
$20: 4 n-3$ & $<0.01$ & $<0.01$ & $<0.01$ \\
$20: 4 n-6$ & $<0.01$ & $<0.01$ & $<0.01$ \\
$20: 5 n-3$ & 0.2 & $<0.01$ & 0.02 \\
$22: 5 n-3$ & $<0.01$ & $<0.01$ & $<0.01$ \\
$22: 6 n-3$ & 1 & $<0.01$ & 0.87 \\
SFA & 0.59 & $<0.01$ & 0.23 \\
MUFA & 0.01 & $<0.01$ & 0.01 \\
$n-6$ PUFA & $<0.01$ & $<0.01$ & $<0.01$ \\
$n-3$ PUFA & 0.13 & $<0.01$ & 0.2 \\
EPA+DHA & 0.4 & $<0.01$ & $<0.01$
\end{tabular}

ppt, Parts per thousand; DPA, docosapentaenoic acid.

$(P<0 \cdot 01)$, while the ARA and EPA contents were remarkably affected by water salinity $(P<0.05)$. When fed the same diets, GIFT in brackish water (12 and $24 \mathrm{ppt}$ ) had a higher liver ARA content than in freshwater $(P<0.05)$, which is similar to the muscle ARA content (Table 6). At the same water salinity, the liver DHA content of D1 group was considerably higher than the two VO groups (D2 and D3 groups) $(P<0.05)$, while the liver DHA content of D3 group (the high-ALA fed group) was also higher than the D2 group (the high-LA fed group) $(P<0.05)$; meanwhile, the liver ARA content of D2 group was significantly higher than the D3 group $(P<0 \cdot 05)$, but showed no significance with the D1 group $(P>0.05)$, which is synonymous with muscle ARA content.

\section{$m R N A$ levels of genes encoding key enzymes involved in long-chain PUFA biosynthesis and their related transcription factors}

The mRNA expression levels of the genes encoding key enzymes required in the LC-PUFA biosynthetic pathway, $\Delta 5 / \Delta 6 \mathrm{fads} 2, \Delta 4$ fads 2 and eloul 5 are shown in Fig. 1, and the mRNA expression of the genes encoding transcription factors (e.g. ppar $\alpha$, srebp-1, hnf $4 \alpha$ and $l x r$ is shown in Fig. 2. The mRNA expression of $\Delta 5 / \Delta 6$ fads 2 was significantly affected by the dietary lipid sources, with a higher expression found in the D2 group compared to the D1 group at the same water salinity $(P<0.05)$. Water salinity significantly affected the mRNA level of elovl5, which was higher at 24 ppt salinity than at 0 ppt salinity $(P<0 \cdot 05)$. The $\Delta 4$ fads $2 \mathrm{mRNA}$ expression was not significantly affected by both the dietary lipid sources and water salinity $(P>0.05)$, while there was an interaction between them $(P<0.05)$. The mRNA level of ppara increased with increasing salinity, which was significantly higher in $24 \mathrm{ppt}$ water than in freshwater $(P<0.05)$. Furthermore, the mRNA levels of srebp-1, bnf $4 \alpha$ and $l x r$ were significantly affected by the dietary lipid sources, and the srebp-1 expression in the D1 group considerably higher than that in the D2 and D3 groups $(P<0.05)$.

\section{Discussion}

Fish, like mammals, require a dietary supply of essential fatty acids (EFA) of the $n-3$ and $n-6$ series that they are unable to synthesise for normal growth and survival, with LC-PUFA being the EFA of the teleost ${ }^{(1,2)}$. The GIFT and its ancestor Nile tilapia (O. niloticus) are reported to have the ability of transforming dietary ALA and LA into LC-PUFA ${ }^{(27,28,30)}$. In the 
Table 7. Liver fatty acid composition of genetically improved farmed tilapia (Oreochromis niloticus) fed with diets D1-D3 at different ambient salinities for 8 weeks

(Mean values with their standard errors, $n 3$ )

\begin{tabular}{|c|c|c|c|c|c|c|c|c|c|c|c|c|c|c|c|c|c|c|}
\hline \multirow{3}{*}{$\frac{\text { Main }}{\text { Fatty acids }}$} & \multicolumn{6}{|c|}{ D1 } & \multicolumn{6}{|c|}{ D2 } & \multicolumn{6}{|c|}{ D3 } \\
\hline & \multicolumn{2}{|c|}{$0 \mathrm{ppt}$} & \multicolumn{2}{|c|}{$12 \mathrm{ppt}$} & \multicolumn{2}{|c|}{$24 \mathrm{ppt}$} & \multicolumn{2}{|c|}{$0 \mathrm{ppt}$} & \multicolumn{2}{|c|}{$12 \mathrm{ppt}$} & \multicolumn{2}{|c|}{$24 \mathrm{ppt}$} & \multicolumn{2}{|c|}{$0 \mathrm{ppt}$} & \multicolumn{2}{|c|}{$12 \mathrm{ppt}$} & \multicolumn{2}{|c|}{$24 \mathrm{ppt}$} \\
\hline & Mean & SEM & Mean & SEM & Mean & SEM & Mean & SEM & Mean & SEM & Mean & SEM & Mean & SEM & Mean & SEM & Mean & SEM \\
\hline $18: 1 n-9$ & $19 \cdot 62$ & 1.67 & $18 \cdot 40$ & 0.37 & 16.98 & 0.51 & 29.55 & 1.53 & 31.69 & 2.53 & 32.54 & 0.68 & 31.55 & 0.86 & 33.02 & 0.98 & 31.94 & 1.55 \\
\hline $18: 2 n-6$ & 3.04 & 0.50 & 5.32 & 0.31 & 4.77 & 0.32 & $10 \cdot 21$ & 1.29 & $15 \cdot 40$ & 0.97 & $12 \cdot 70$ & 0.55 & $5 \cdot 38$ & 0.79 & 5.04 & 0.64 & $5 \cdot 23$ & $1 \cdot 27$ \\
\hline $18: 3 n-3$ & 0.49 & 0.08 & 1.53 & 0.12 & 1.47 & 0.20 & 1.43 & 0.36 & 1.96 & 0.20 & 3.09 & 0.24 & $7 \cdot 06$ & 0.11 & $6 \cdot 36$ & 0.45 & $7 \cdot 13$ & 1.01 \\
\hline $20: 2 n-6$ & 0.72 & 0.17 & 0.82 & 0.07 & 0.56 & 0.12 & 0.54 & 0.07 & 1.00 & 0.17 & 0.67 & 0.06 & 0.36 & 0.03 & 0.51 & 0.04 & 0.69 & 0.11 \\
\hline $20: 4 n-3$ & 1.29 & 0.15 & $1 \cdot 13$ & 0.04 & 1.87 & 0.38 & 3.02 & $1 \cdot 11$ & 3.41 & 0.76 & $2 \cdot 62$ & 0.15 & 0.81 & 0.08 & 1.02 & 0.08 & $1 \cdot 25$ & 0.22 \\
\hline $20: 4 n-6$ (ARA) & $1 \cdot 72$ & 0.09 & $2 \cdot 14$ & 0.06 & 0.80 & 0.14 & $2 \cdot 44$ & 0.42 & $1 \cdot 21$ & $0 \cdot 16$ & 0.81 & 0.05 & 0.61 & 0.07 & 0.77 & 0.11 & 0.88 & 0.34 \\
\hline $20: 5 n-3$ (EPA) & 3.26 & 0.26 & $3 \cdot 23$ & 0.22 & 3.31 & 0.26 & 1.07 & 0.18 & $2 \cdot 81$ & $0 \cdot 16$ & 0.79 & 0.07 & 0.81 & 0.08 & 1.76 & 0.06 & $2 \cdot 18$ & 049 \\
\hline $22: 5 n-3$ (DPA) & 4.23 & 0.09 & 3.57 & 0.12 & $2 \cdot 77$ & 0.83 & $6 \cdot 20$ & 0.26 & 3.65 & 0.95 & 2.56 & 0.31 & $2 \cdot 13$ & 0.05 & 1.55 & 0.40 & 3.49 & $1 \cdot 13$ \\
\hline $22: 6 n-3$ (DHA) & $19 \cdot 16$ & $1 \cdot 10$ & $18 \cdot 79$ & 0.92 & $20 \cdot 10$ & 1.41 & 7.35 & 0.66 & 8.08 & $0 \cdot 10$ & $7 \cdot 72$ & 0.99 & $10 \cdot 29$ & 0.59 & $10 \cdot 90$ & 0.68 & 10.56 & 0.68 \\
\hline SFA & $37 \cdot 32$ & 0.56 & 36.50 & 0.61 & $38 \cdot 10$ & 0.41 & $30 \cdot 72$ & 0.39 & 28.55 & 1.22 & $29 \cdot 46$ & 0.48 & 32.56 & 0.61 & $33 \cdot 12$ & 1.34 & 29.89 & 1.42 \\
\hline MUFA & $24 \cdot 16$ & 0.99 & 22.43 & 0.40 & 21.52 & $1 \cdot 24$ & 31.72 & 1.64 & $34 \cdot 38$ & 2.69 & $35 \cdot 62$ & 0.75 & 35.00 & 0.87 & 35.48 & $1 \cdot 15$ & 34.63 & 1.84 \\
\hline$n-6$ PUFA & 5.48 & 0.42 & $8 \cdot 29$ & 0.35 & $6 \cdot 14$ & 0.13 & $13 \cdot 19$ & 0.82 & $17 \cdot 61$ & 0.67 & $14 \cdot 18$ & 0.54 & $6 \cdot 34$ & 0.84 & $6 \cdot 32$ & 0.50 & $6 \cdot 80$ & 0.90 \\
\hline$n$-3 PUFA & $24 \cdot 20$ & 1.04 & $24 \cdot 67$ & 0.61 & $26 \cdot 74$ & 0.70 & $12 \cdot 86$ & 1.84 & $16 \cdot 26$ & $0 \cdot 81$ & $14 \cdot 24$ & 1.02 & 18.96 & 0.45 & $20 \cdot 04$ & 0.26 & $21 \cdot 12$ & 0.56 \\
\hline$D H A+E P A$ & 23.39 & 1.19 & $22 \cdot 36$ & 1.03 & $22 \cdot 86$ & $2 \cdot 12$ & 13.55 & 0.92 & 11.73 & 1.05 & $10 \cdot 28$ & 1.30 & 12.42 & 0.56 & 12.45 & 0.33 & 14.05 & 1.78 \\
\hline
\end{tabular}

\begin{tabular}{lrrr} 
& & $P$ (two-way ANOVA) & \\
\cline { 2 - 4 } Fatty acid & Salinity & Diet & Salinity $\times$ diet interaction \\
\hline $18: 1 n-9$ & 0.76 & $<0.01$ & 0.37 \\
$18: 2 n-6$ & $<0.01$ & $<0.01$ & 0.05 \\
$18: 3 n-3$ & 0.04 & $<0.01$ & 0.17 \\
$20: 2 n-6$ & 0.04 & 0.04 & 0.07 \\
$20: 4 n-3$ & 0.86 & $<0.01$ & 0.60 \\
$20: 4 n-6$ & $<0.01$ & $<0.01$ & $<0.01$ \\
$20: 5 n-3$ & $<0.01$ & $<0.01$ & $<0.01$ \\
$22: 5 n-3$ & 0.03 & $<0.01$ & $<0.01$ \\
$22: 6 n-3$ & 0.76 & $<0.01$ & 0.87 \\
SFA & 0.33 & $<0.01$ & 0.08 \\
MUFA & 0.92 & $<0.01$ & 0.27 \\
$n-6$ PUFA & $<0.01$ & $<0.01$ & 0.02 \\
$n-3$ PUFA & 0.03 & $<0.01$ & 0.26 \\
DHA +EPA & 0.64 & $<0.01$ & 0.45 \\
\hline
\end{tabular}

ppt, Parts per thousand; DPA, docosapentaenoic acid.

present study, the WGR, SGR and FCR of the two VO (free LCPUFA)-fed groups showed no significance with the FO (with LCPUFA) group, indicating that the dietary FO of the GIFT can be entirely replaced by VO with no negative effects on the growth. Furthermore, the dietary high-LA group improved liver ARA content, while the dietary high-ALA group promoted liver DHA content. It is suggested that the GIFT indeed possesses the LC-PUFA bioconversion ability, and is capable of effectively using dietary ALA and LA to meet the EFA requirements for normal growth and physiology. Moreover, the growth performance of the GIFT was considerably correlated with water salinity in the present study, which was better at $12 \mathrm{ppt}$ than at $0 \mathrm{ppt}$, suggesting that GIFT may have a higher LC-PUFA bioconversion ability in brackish water than in freshwater. This finding was further confirmed by the liver and muscle fatty acid composition of the GIFT under different water salinities, whereby a higher liver and muscle ARA content was observed in brackish water of 12 and 24 ppt compared with 0 ppt water. Although the mRNA expression of the key enzymatic genes $\Delta 5 / \Delta 6$ fads 2 and $\Delta 4$ fads 2 showed no significance among different salinity treatments, the key enzymatic gene elovl5 and the transcription factor ppar $\alpha$ showed a higher expression in $24 \mathrm{ppt}$ water than in 0 ppt water in the liver of GIFT. This suggests that elovl5 and ppara might be involved in the regulation of LC-PUFA biosynthesis by water salinity in tilapia, which is similar to the observations in the rabbitfish $S$. canaliculatus and Atlantic salmon

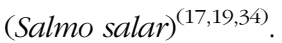

Environmental salinity might correlate with endogenous LCPUFA biosynthesis of fish in terms of the following: (1) LC-PUFA are the major phospholipid components of cell membranes, which establish the fluidity and permeability of the membranes ${ }^{(35,36)}$, and when environmental salinity changes, membrane fatty acid composition is also altered to properly maintain the osmotic pressure balanced inside and outside the body of fish ${ }^{(37)}$. (2) Lipids are an important energy source in animals through fatty acid $\beta$-oxidation. The liver and muscle are the most active tissues for fatty acid $\beta$-oxidation in fish ${ }^{(38)}$. Thus, fatty acid composition in liver and muscle might change during variation of environmental salinity. (3) Salinity might indirectly regulate the synthesis of LC-PUFA by adjusting the hormone levels in fish, such as auxin, cortisol, prolactin and insulin-like growth factor- $1^{(39,40)}$. The previous study reported that O. niloticus, the ancestor of GIFT, showed the best growth performance in freshwater ${ }^{(29)}$. However, Qiang et al. ${ }^{(41)}$ reported that the optimal water salinity was $7 \cdot 8 \mathrm{ppt}$ for the GIFT. 
(a)

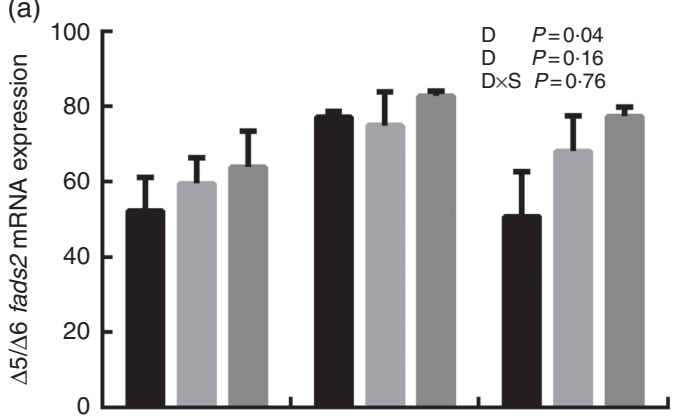

(b)

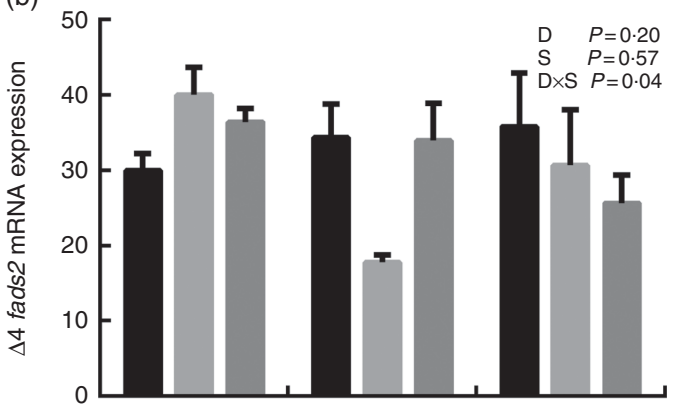

(c)

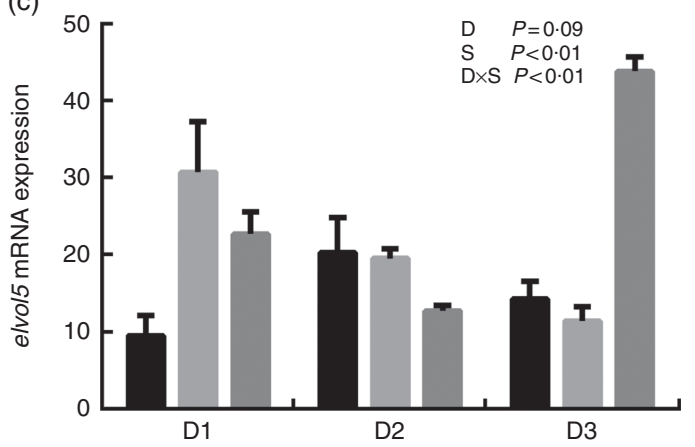

Fig. 1. mRNA expression of $\Delta 5 / \Delta 6$ fatty acyl desaturase (fads2) (a), $\Delta 4$ fads2 (b) and elongase 5 of very long-chain fatty acids (elov/5) (c) in liver of genetically improved farmed tilapia (Oreochromis niloticus) fed D1, D2 and D3 diets at $0 \%$ (parts per thousand; ppt) $(\square), 12 \mathrm{ppt}(\square)$ and $24 \mathrm{ppt}(\square)$ salinities, respectively. The mRNA levels of target genes were determined by quantitative $\mathrm{PCR}$, using $\beta$-actin as a reference gene. Values are means $(n 6)$, with their standard errors represented by vertical bars.

The present study also reveals that GIFT is the best appropriate to live in brackish water (12ppt) among the three salinity treatments $(0,12$ and $24 \mathrm{ppt})$, indicating a wider tolerance to water salinity compred to its ancestor O. niloticus. It can therefore be speculated that GIFT might maintain osmotic equilibrium through changes in the endogenous LC-PUFA biosynthetic capacity to alter the fatty acid composition and membrane fluidity of cellular membrane during variations in water salinity, when the membrane-associated proteins (receptors, enzymes, etc.) are affected ${ }^{(37,42)}$. However, unlike the GIFT, low salinity stimulates endogenous synthesis of LCPUFA in $S$. canaliculatus and decreases the growth performance ${ }^{(16,17)}$. S. canaliculatus spawns in seawater and its larva migrate and live in shallow sea areas, therefore, seawater with high salinity is appropriate for its growth. Thus, low salinity would be a challenge for the rabbitfish $S$. canaliculatus. Nile tilapia O. niloticus, the ancestor of GIFT, originated from the freshwater environment of the Tanganyika Lake of Africa and is appropriate to live in freshwater ${ }^{(25,29)}$. However, the brackish water (12 ppt) simultaneously promoted the endogenous LCPUFA bioconversion ability as well as the growth performance of the GIFT, suggesting GIFT is comfortable to live in the brackish water similar to what was observed in the silverside Chirostoma estor ${ }^{(37)}$. The association between water salinity and LC-PUFA biosynthesis in fish is variable among species and seems to depend on whether water salinity is the actual challenge for the fish species ${ }^{(37)}$. The precise mechanistic links between these require further investigation.

The effects of water salinity on fish growth might also be related to energy consumption, which is used to sustain body osmotic equilibrium ${ }^{(34,37)}$. When water salinity changes, a large amount of energy is consumed to maintain the osmotic equilibrium inside and outside the fish body. This energy consumption is detrimental to the nutrient accumulation and then suppresses fish growth ${ }^{(43)}$. Thus, when water salinity varied from the optimal salinity for fish, there was a decrease in the crude protein contents of Mugil cephalus and L. japonicus ${ }^{(44,45)}$, and the crude lipid content of $S$. canaliculatus and O. niloticus was also observed to decline ${ }^{(17,46)}$. In the present study, the crude protein and lipid contents of the GIFT were not remarkably affected by water salinities ( $0-24 \mathrm{ppt})$. These results could be attributed to the strong adaptive ability of the GIFT to environmental salinity, which is even stronger than its ancestor $O$. niloticus. A similar phenomenon was observed in O. mykiss, with no significant differences in the fish lipid content under different salinities $(15,20 \text { and } 33 \mathrm{ppt})^{(47)}$. It thus suggests that the GIFT has a better salt tolerance than its ancestor O. niloticus.

In the LC-PUFA biosynthetic pathway of fish, LA and ALA are competitive substrates of $\Delta 6$ Fads2 desaturase, the first ratelimiting enzyme in the production of LC-PUFA. Thus, various fish have their distinct preferences for dietary fatty acids, hence the proper dietary LA:ALA ratio will vary among fish species ${ }^{(48)}$. In the present study, although the different dietary groups showed no significance in growth, the GIFT in high-LA group (LA:ALA $=4.04$ ) showed the best growth performance and the highest $\Delta 5 / \Delta 6$ fads 2 expression under all salinity treatments. This suggests that the GIFT prefers the high-LA diets and is able to fully compensate for the lack of dietary LC-PUFA when fed with the VO diets. These results were consistent with the previous studies ${ }^{(30,49)}$. Therefore, in terms of growth, FO can be entirely replaced with $\mathrm{VO}$ in the formulated feeds of the GIFT with the proper dietary LA:ALA ratio of $4 \cdot 04$.

\section{Conclusions}

By the 8-week feeding trial, the results revealed that FO can be fully replaced with VO in diets of the GIFT without a negative effect on the growth; GIFT had a better growth performance at $12 \mathrm{ppt}$, coupled with a higher liver and muscle ARA content at $12 \mathrm{ppt}$ and $24 \mathrm{ppt}$ than in freshwater. It is suggested that brackish water (12 ppt and $24 \mathrm{ppt}$ ) can promote the growth performance and increase the LC-PUFA bioconversion ability of the GIFT compared with freshwater, probably by enhancing the expression levels of genes related to LC-PUFA biosynthesis, 
(a)

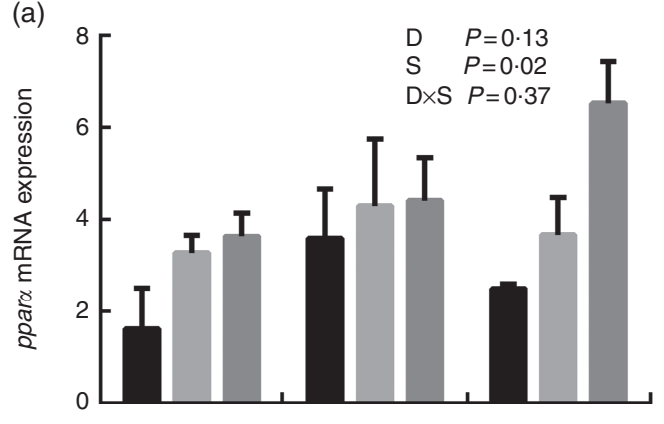

(c)

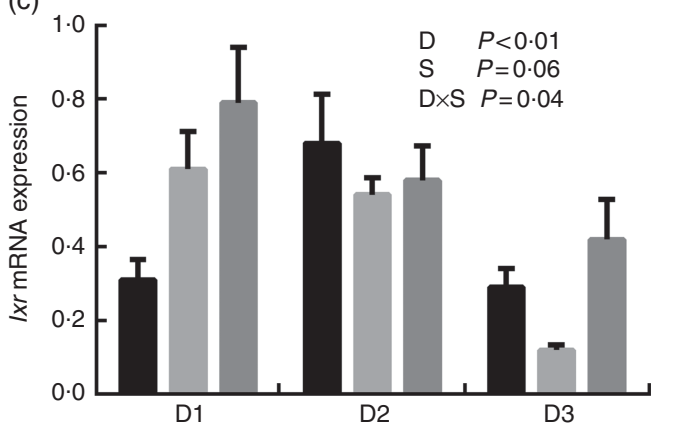

(b)

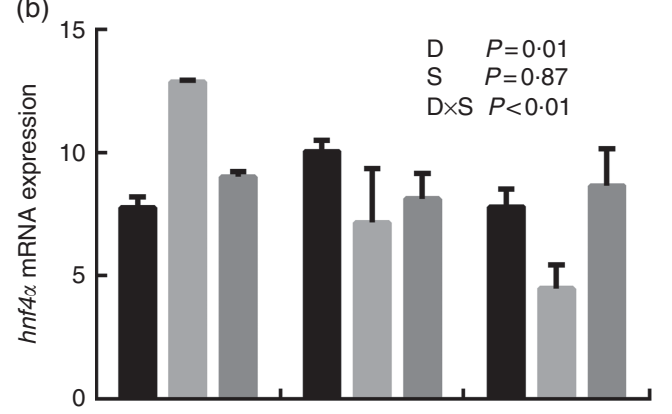

(d)

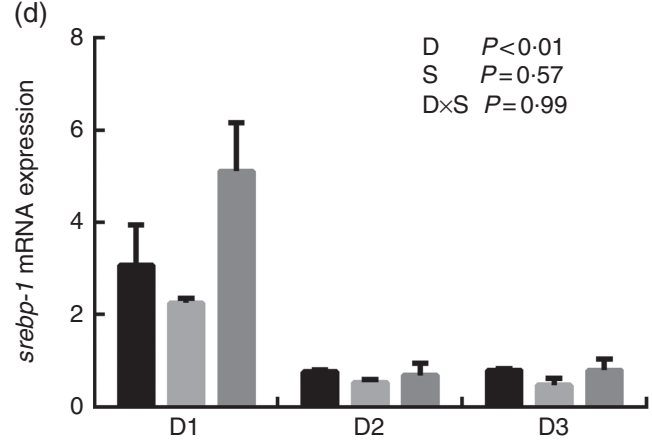

Fig. 2. mRNA expression of peroxisome proliferator-activated receptor $a$ (ppara) (a), hepatocyte nuclear factor $4 a(h n f 4 a)$ (b), liver $\mathrm{X}$ receptor (Ixr) (c) and sterol regulatory element-binding protein-1 (srebp-1) (d) in liver of genetically improved farmed tilapia (Oreochromis niloticus) fed D1, D2 and D3 diets at $0 \%$ (parts per thousand; ppt) ( $\square$ ), $12 \mathrm{ppt}(\square)$ and $24 \mathrm{ppt}(\square)$ salinities, respectively. The mRNA levels of target genes were determined by quantitative PCR, using $\beta$-actin as a reference gene. Values are means $(n 6)$, with their standard errors represented by vertical bars.

such as elovl5 and ppara. Besides, GIFT prefers the high-LA diets, with the LA/ALA ratio of $4 \cdot 04$.

\section{Acknowledgements}

The authors thank Dr Aweya Jude Juventus of Shantou University for revising the manuscript.

This work was financially supported by National Natural Science Foundation of China (nos 31873040 and 31110103913) and China Agriculture Research System (CARS-47).

Y. L. designed the study; F. L. carried out the growth experiment; S. W. assisted with the fatty acid analyses; C. C. performed the gene expression analyses; C. Y. and F. L. analysed the data; C. Y. wrote the paper with the help from Y. L.; all authors contributed to and approved the manuscript.

The authors declare that there are no conflicts of interest.

\section{References}

1. Sargent JR, Bell JG, Bell MV, et al. (1995) Requirement criteria for essential fatty acids. J Appl Ichthyol 11, 183-198.

2. Tocher DR (2003) Metabolism and functions of lipids and fatty acids in teleost fish. Rev Fish Sci 11, 107-184.

3. Lorente-Cebrián S, Costa AG, Navas-Carretero S, et al. (2013) Role of omega- 3 fatty acids in obesity, metabolic syndrome, and cardiovascular diseases: a review of the evidence. J Physiol Biochem 69, 633-651.

4. Castro LFC, Monroig Ó, Leaver MJ, Wilson J, et al. (2012) Functional desaturase Fads1 $(\Delta 5)$ and Fads2 $(\Delta 6)$ orthologues evolved before the origin of jawed vertebrates. PLOS ONE 7, e31950.
5. Zheng X, Tocher DR, Dickson CA, et al. (2005) Highly unsaturated fatty acid synthesis in vertebrates: new insights with the cloning and characterization of a $\Delta 6$ desaturase of Atlantic salmon. Lipids 40, 13-24.

6. Bond LM, Miyazaki M, ÓNeill LM, et al. (2016) Chapter 6 - fatty acid desaturation and elongation in mammals. In Biochemistry of Lipids, Lipoproteins and Membranes, 6th ed., pp. 185-208 [ND Ridgway, RS McLeod, editors]. The Netherlands: Elsevier.

7. Castro LFC, Tocher DR \& Monroig O (2016) Long-chain polyunsaturated fatty acid biosynthesis in chordates: insights into the evolution of Fads and Elovl gene repertoire. Progr Lipid Res 62, 25-40.

8. Hastings N, Agaba M, Tocher DR, et al. (2001) A vertebrate fatty acid desaturase with $\Delta 5$ and $\Delta 6$ activities. Proc Natl Acad Sci U S A 98, 14304-14309.

9. Morais S, Monroig O, Zheng X, et al. (2009) Highly unsaturated fatty acid synthesis in Atlantic salmon: isolation of genes of fatty acyl elongases and characterization of ELOVL5- and ELOVL2-like elongase cDNA. Mar Biotechnol 11, 627-639.

10. Qin Y, Dalen KT, Gustafsson JA, et al. (2009) Regulation of hepatic fatty acid elongase 5 by LXR $\alpha$-SREBP-1c. Biochim Biophys Acta 1791, 140-147.

11. Carmona-Antonanzas G, Tocher DR, Martinez-Rubio L, et al. (2014) Conservation of lipid metabolic gene transcriptional regulatory networks in fish and mammals. Gene 534, 1-9.

12. Dong X, Tan P, Cai Z, et al. (2017) Regulation of FADS2 transcription by SREBP-1 and PPAR- $\alpha$ influences LC-PUFA biosynthesis in fish. Sci Rep 7, 40024.

13. Fernandez-Alvarez A, Alvarez MS, Gonzalez R, et al. (2011) Human SREBP1c expression in liver is directly regulated by peroxisome proliferator-activated receptor alpha (PPARalpha). J Biol Chem 286, 21466-21477.

14. Dong Y, Wang S, Chen J, et al. (2016) Hepatocyte nuclear factor $4 \alpha(\operatorname{HNF} 4 \alpha)$ is a transcription factor of vertebrate fatty 
acyl desaturase gene as identified in marine teleost Siganus canaliculatus. PLOS ONE 11, e0160361.

15. Wang S, Chen J, Jiang DL, et al. (2018) Hnfualpha is involved in the regulation of vertebrate LC-PUFA biosynthesis: insights into the regulatory role of Hnf4alpha on expression of liver fatty acyl desaturases in the marine teleost Siganus canaliculatus. Fish Physiol Biochem 44, 805-815.

16. Li YY, Hu CB, Zheng YJ, et al. (2008) The effects of dietary fatty acids on liver fatty acid composition and delta (6)-desaturase expression differ with ambient salinities in Siganus canaliculatus. Comp Biochem Physiol B 151, 183-190.

17. Xie D, Wang S, You C, et al. (2015) Characteristics of LC-PUFA biosynthesis in marine herbivorous teleost Siganus canaliculatus under different ambient salinities. Aquac Nutr 21, 541-551.

18. Zhang Q, You C, Liu F, et al. (2016) Cloning and characterization of Lxr and Srebp1, and their potential roles in regulation of LC-PUFA biosynthesis in rabbitfish Siganus canaliculatus. Lipids 51, 1051-1063.

19. You C, Jiang D, Zhang Q, et al. (2017) Cloning and expression characterization of peroxisome proliferator-activated receptors (PPARs) with their agonists, dietary lipids, and ambient salinity in rabbitfish Siganus canaliculatus. Comp Biochem Physiol B 206, 54-64.

20. Sarker MA, Yamamoto Y, Haga Y, et al. (2011) Influences of low salinity and dietary fatty acids on fatty acid composition and fatty acid desaturase and elongase expression in red sea bream Pagrus major. Fisheries Sci 77, 385-396.

21. Xie DZ, Liu XB, Wang SQ, et al. (2018) Effects of dietary LNA/ LA ratios on growth performance, fatty acid composition and expression levels of elovl5, $\Delta 4 \mathrm{fad}$ and $\Delta 6 / \Delta 5 \mathrm{fad}$ in the marine teleost Siganus canaliculatus. Aquaculture 484, 309-316.

22. Liu ZF, Gao XQ, Yu JX, et al. (2017) Effects of different salinities on growth performance, survival, digestive enzyme activity, immune response, and muscle fatty acid composition in juvenile American shad (Alosa sapidissima). Fish Physiol Biochem 43, 761-773

23. Haliloğlu Hİ, Bayır A, Sirkecioğlu AN, et al. (2004) Comparison of fatty acid composition in some tissues of rainbow trout (Oncorbynchus mykiss) living in seawater and freshwater. Food Chem 86, 55-59.

24. Xu J, Yan B, Teng Y, et al. (2010) Analysis of nutrient composition and fatty acid profiles of Japanese sea bass Lateolabrax japonicus (Cuvier) reared in seawater and freshwater. J Food Compos Anal 23, 401-405.

25. Brummett RE \& Alon NC (1994) Polyculture of Nile tilapia (Oreochromis niloticus) and Australian red claw crayfish (Cherax quadricarinatus) in earthen ponds. Aquaculture 122, 47-54.

26. Yuan Y, Yuan Y, Dai Y, et al. (2017) Economic profitability of tilapia farming in China. Aquac Int 1, 1-12.

27. Tocher DR, Agaba M, Hastings N, et al. (2001) Nutritional regulation of hepatocyte fatty acid desaturation and polyunsaturated fatty acid composition in zebrafish (Danio rerio) and tilapia (Oreochromis niloticus). Fish Physiol Biochem 24, 309-320.

28. Agaba MK, Tocher DR, Zheng X, et al. (2005) Cloning and functional characterisation of polyunsaturated fatty acid elongases of marine and freshwater teleost fish. Comp Biochem Physiol B 142, 342-352.

29. Gan L, Xu ZX, Ma JJ, et al. (2016) Effects of salinity on growth, body composition, muscle fatty acid composition, and antioxidant status of juvenile Nile tilapia Oreochromis niloticus (Linnaeus, 1758). J Appl Ichthyol 32, 372-374

30. Teoh C, Turchini GM \& Ng W (2011) Genetically improved farmed Nile tilapia and red hybrid tilapia showed differences in fatty acid metabolism when fed diets with added fish oil or a vegetable oil blend. Aquaculture 312, 126-136.
31. Chen CY, Guan WT, Xie QM, et al. (2018) n-3 essential fatty acids in Nile tilapia, Oreochromis niloticus: bioconverting LNA to DHA is relatively efficient and the LC-PUFA biosynthetic pathway is substrate limited in juvenile fish. Aquaculture 495, 513-522.

32. Oboh A, Kabeya N, Carmona-Aotoanzs G, et al. (2017) Two alternative pathway for docosahexaenoic acid (DHA, 22:6n-3) biosynthesis are widespread among teleost fish. Sci Rep 7, 3889.

33. Livak KJ \& Schmittgen TD (2001) Analysis of relative gene expression data using real-time quantitative PCR and the $2^{-\Delta \Delta C}$ method. Methods 25, 402-408.

34. Zheng X, Torstensen BD, Dick J, et al. (2005) Environmental and dietary influences on highly unsaturated fatty acid biosynthesis and expression of fatty acyl desaturase and elongase genes in liver of Atlantic salmon (Salmo salar). Biochim Biophys Acta 1734, 13-24.

35. Borlongan IG \& Benitez LV (1992) Lipid and fatty acid composition of milkfish (Chanos chanos Forsskal) grown in freshwater and seawater. Aquaculture 104, 79-89.

36. Mourente G, Bell JG \& Tocher DR (2007) Does dietary tocopherol level affect fatty acid metabolism in fish? Fish Physiol Biochem 33, 269-280.

37. Fonseca-Madrigal J, Pineda-Delgado D, Martínez-Palacios C, et al. (2012) Effect of salinity on the biosynthesis of $n-3$ longchain polyunsaturated fatty acids in silverside Chirostoma estor. Fish Physiol Biochem 38, 1047-1057.

38. Fonseca-Madrigal J, Bell JG \& Tocher DR (2006) Nutritional and environmental regulation of the synthesis of highly unsaturated fatty acids and of fatty-acid oxidation in Atlantic salmon (Salmo salar L.) enterocytes and hepatocytes. Fish Physiol Biochem 32, 317-328.

39. Saltiel AR \& Kahn CR (2001) Insulin signalling and the regulation of glucose and lipid metabolism. Nature 414, 799-806.

40. Vagner M, Robin JH, Zamboninoinfante JL, et al. (2009) Ontogenic effects of early feeding of sea bass (Dicentrarchus labrax) larvae with a range of dietary $n-3$ highly unsaturated fatty acid levels on the functioning of polyunsaturated fatty acid desaturation pathways. BrJ Nutr 101, 1452-1462.

41. Qiang J, Wang H, Kpundeh MD, et al. (2013) ) Effect of water temperature, salinity, and their interaction on growth, plasma osmolality, and gill $\mathrm{Na}^{+}, \mathrm{K}^{+}$-ATPase activity in juvenile GIFT tilapia Oreochromis niloticus (L.). J Therm Biol 38, 331-338.

42. Leray C, Chapelle S, Duportail G, et al. (1984) Changes in fluidity and 22:6(n-3) content in phospholipids of trout intestinal brush-border membrane as related to environmental salinity. Biochim Biophys Acta 778, 233-238.

43. Boeuf G \& Payan P (2001) How should salinity influence fish growth? Comp Biochem Physiol C 130, 411-423.

44. Kheriji S, El CM, Masmoudi W, et al. (2003) Salinity and temperature effects on the lipid composition of mullet sea fry (Mugil cephalus, Linne, 1758). Aquac Int 11, 571-582.

45. Xu J, Yan B, Teng Y, et al. (2010) Analysis of nutrient composition and fatty acid profiles of Japanese sea bass Lateolabrax japonicus (Cuvier) reared in seawater and freshwater. J Food Compos Anal 23, 401-405.

46. Gan L, Xu ZX, Ma JJ, et al. (2016) Effects of salinity on growth, body composition, muscle fatty acid composition, and antioxidant status of juvenile Nile tilapia Oreochromis niloticus (Linnaeus, 1758). J Appl Ichthyol 32, 372-374.

47. Haliloğlu Hi, Bayır A, Sirkecioğlu AN, et al. (2004) Comparison of fatty acid composition in some tissues of rainbow trout (Oncorbynchus mykiss) living in seawater and freshwater. Food Chem 86, 55-59.

48. Glencross BD (2009) Eploring the nutritional demand for essential fatty acids by aquaculture species. Rev Aquac 1, 71-124.

49. Young K (2009) Omega-6 ( $n-6)$ and omega-3 (n-3) fatty acids in tilapia and human health: a review. Int J Food Sci and Nutr 60, 203-211. 